\title{
Expression of TRPM8 in human reactive lymphoid tissues and mature B-cell neoplasms
}

\author{
AKINORI HIRAI $^{1}$, NAING YE AUNG ${ }^{1}$, RINTARO OHE $^{1}$, AKIKO NISHIDA $^{2}$, TOMOYA KATO ${ }^{1}$, \\ HONGXUE MENG $^{1}$, KENICHI ISHIZAWA ${ }^{3}$, JUNICHI FUJII ${ }^{4}$ and MITSUNORI YAMAKAWA ${ }^{1}$ \\ ${ }^{1}$ Department of Pathological Diagnostics, Yamagata University Faculty of Medicine, Yamagata, Yamagata 990-9585; \\ ${ }^{2}$ Division of Pathology, Nihonkai General Hospital, Sakata, Yamagata 998-8501; ${ }^{3}$ Third Department of Internal Medicine; \\ ${ }^{4}$ Department of Biochemistry and Molecular Biology, Yamagata University \\ Faculty of Medicine, Yamagata, Yamagata 990-9585, Japan
}

Received February 1, 2018; Accepted July 30, 2018

DOI: $10.3892 / \mathrm{ol} .2018 .9386$

\begin{abstract}
Transient receptor potential melastatin 8 (TRPM8) is a member of the transient receptor potential superfamily of $\mathrm{Ca}^{2+}$ channels. The aim of the present study was to clarify TRPM8 expression in reactive lymphoid tissues and mature B-cell neoplasms. Reactive and neoplastic lymphoid tissues were used to evaluate TRPM8 expression by immunohistochemistry and reverse transcription-polymerase chain reaction (RT-PCR). TRPM8 ${ }^{+}$cells were frequently detected in the follicular light zone and marginal zone of reactive lymphoid tissues. Double immunostaining revealed that TRPM $8^{+}$cells co-expressed cluster of differentiation (CD) 38, CD79a, CD138, interferon regulatory factor $4 /$ melanoma associated antigen (mutated) 1, B cell CLL/lymphoma 6 and transmembrane activator and CAML interactor. TRPM8 ${ }^{+}$neoplastic cells were frequently detected in plasma cell myeloma. The positive band of TRPM8 mRNA was confirmed by RT-PCR in cases of myeloma. The present study is, to the best of our knowledge, the first to demonstrate the expression of TRPM 8 in reactive lymphoid tissues and mature B-cell neoplasms, revealing that TRPM8 is frequently expressed in pre-plasmablasts, plasmablasts, plasma cells and mature B-cell lymphomas that are likely to differentiate into plasma cells.
\end{abstract}

\section{Introduction}

When naive $\mathrm{B}$ cells are activated by antigens, they differentiate into activated $\mathrm{B}$ cells $\left(\mathrm{CD} 20^{+} \mathrm{CD} 38^{ \pm} \mathrm{CD} 138^{-}\right)$, pre-plasmablasts $\left(\mathrm{CD} 20^{ \pm} \mathrm{CD} 38^{+} \mathrm{CD} 138^{-}\right)$, and plasmablasts

Correspondence to: Professor Mitsunori Yamakawa, Department of Pathological Diagnostics, Yamagata University Faculty of Medicine, 2-2-2 Iida-Nishi, Yamagata 990-9585, Japan

E-mail: myamakaw@med.id.yamagata-u.ac.jp

Key words: transient receptor potential melastatin 8, mature B-cell neoplasms, lymphoid follicle, plasma cell myeloma, immunohistochemistry
(CD20-CD38 $\left.{ }^{+++} \mathrm{CD} 138^{-}\right)$in lymphoid follicles, followed by early plasma cells (PCs; CD20-CD38 $8^{+++} \mathrm{CD} 138^{++}$) and then late PCs $\left(\mathrm{CD} 19^{+} \mathrm{CD} 20^{-} \mathrm{CD} 38^{+++} \mathrm{CD} 138^{+++}\right)$in extrafollicular areas, including bone marrow (1-3). PCs are mainly distributed in the lymphoepithelial symbiosis (SYM) /marginal zone (MZ) of the tonsils, the MZ and medullary cord of the lymph nodes (LN), and the dome of Peyer's patches.

Mature B-cell neoplasms correspond to the clonal proliferation of mature B cells derived from naive B cells to $\mathrm{PCs}$ in the normal B-cell differentiation pathway. Since the nature of neoplastic B cells may mimic that of normal $B$ cells at each differentiation stage, the nomenclature and classification of these neoplasms are based on their differentiation stages (4). The clonal expansion of terminally differentiated B cells is generally called plasma cell neoplasm (PCN) (5). Although a number of antibodies that recognize PCN cells have been reported in the literature, only a few antibodies, including CD38, CD56, CD79a, CD117, CD138, and interferon-regulating factor 4/multiple myeloma oncogene 1 (IRF4/MUM-1), are valuable for and applicable to formalin-fixed and paraffin-embedded tissue sections (3,6-8).

Transient receptor potential melastatin 8 (TRPM8) is a member of the transient receptor potential (TRP) superfamily of $\mathrm{Ca}^{2+}$-permeable non-selective cation channels (9-11). This channel was identified by Tsavaler et al (12) as a novel prostate-specific protein that is up-regulated in prostate cancer $(13,14)$. This protein was also identified in the sensory nerves of spinal dorsal root ganglia, and because it activates the cellular influx of $\mathrm{Ca}^{2+}$ across the plasma membrane with cold stimuli $\left(8-28^{\circ} \mathrm{C}\right)$, including cooling agents such as menthol, this channel protein is regarded as a cold thermoreceptor (15-20).

TRPM8 has been found in approximately 10 types of malignant tumors including carcinomas derived from the prostate gland, mammary gland, oral cavity, colon, lung, skin, pancreas, and urinary bladder (12-14,21-26). Furthermore, murine lymphocytes express several subtypes of the TRP superfamily (27-29); however, it currently remains unclear whether TRPM8 localizes in human reactive lymphoid tissues and malignant lymphomas.

The aim of the present study was to clarify the expression of TRPM8 in reactive lymphoid tissues and mature B-cell 
neoplasms. We herein demonstrated for the first time that pre-plasmablasts and plasmablasts in germinal centers (GC), and PCs in the extrafollicular areas of reactive lymphoid tissues as well as some mature B-cell neoplasms express TRPM8.

\section{Patients and methods}

Patients and specimens. Tissue specimens resected from patients with chronic tonsillitis $(n=5)$, reactive lymphadenitis $(n=5)$, and acute appendicitis $(n=5)$ were used as reactive lymphoid tissues. Tissue specimens were collected from LNs, bone marrow, gastrointestinal tract and kidney which were pathologically diagnosed as malignant B-cell neoplasms. Mature B-cell neoplasms included 3 cases of small lymphocytic lymphoma (SLL) [2 males, 1 female; median age, 46.7 years (range, 31-68)], 4 cases of lymphoplasmacytic lymphoma (LPL) [3 males, 1 female; median age, 65.0 years (range, 47-80)], 16 cases of PCN including 3 cases of monoclonal gammopathy of undetermined significance (MGUS) [3 females; median age, 62.0 years (range, 60-75)], 12 cases of plasma cell myeloma (PCM) including 6 cases of $\operatorname{IgG}$ type [ 3 males, 3 females; median age, 63.5 years (range, 40-83)], 6 cases of IgA type [4 males, 2 females; median age, 65.2 years (range, 19-81)], 1 case of extraosseous plasmacytoma [1 male; age, 73 years], 5 cases of extranodal MZ lymphoma of mucosa-associated lymphoid tissue (MALT lymphoma) [2 males, 3 females; median age, 70.0 (range, 53-80)], 5 cases of follicular lymphoma (FL) [only cases of a follicular pattern of $>75 \%$ were selected, 1 male, 4 females; median age, 63.5 (range, 59-58)], 3 cases of mantle cell lymphoma (MCL) [except variants, 2 males, 1 female; median age, 69.0 (range, 62-73)], and 18 cases of the centroblastic and immunoblastic subtypes of common morphological variants of diffuse large B-cell lymphoma (DLBCL) including 7 cases of GC B-cell like (GCB) [3 males, 4 females; median age, 55.43 years (range, 8-81)] and 11 cases of non-GCB [5 males, 6 females; median age, 70.64 (range, 53-78)] as immunohistochemical subgroups (30). These tissue specimens were fixed in buffered $10 \%$ formalin at room temperature for 6-12 $\mathrm{h}$, and then embedded in paraffin and used for immunohistochemistry. Formalin-fixed and paraffin-embedded tissue specimens resected from 4 patients with well-differentiated prostatic carcinoma were used as controls for immunohistochemistry and from one patient for the reverse transcription polymerase chain reaction (RT-PCR). Fresh-frozen tissue specimens obtained from patients with PCM (n=2) were used for RT-PCR.

Written informed consent was obtained from each patient. The use of tissues and clinical information study was approved by the Ethics Committee of Yamagata University School of Medicine (no. 23).

Immunohistochemistry. Immunohistochemistry was performed using a rabbit polyclonal anti-human TRPM8 antibody [Alomone, Jerusalem, Israel; diluted titer of 1/200; recognizes the peptide SDVD GTTYDFAHC corresponding to amino acid residues 917-929 in the 3rd extracellular loop of human TRPM8 (Accession Q7Z2W7)] (31) as a primary antibody. Regarding the specificity of TRPM8 immunostaining, the antibody was pre-incubated for $2 \mathrm{~h}$ with decreasing concentrations of the peptide to TRPM8 before incubating with the tissue section (antigen-preabsorption). In detail about antigen-preabsorption, the provided antigen of TRPM8 reacted with the antibodies in the used primary antibody. And then, the slides were incubated with this mixture and performed the continued steps of IHC. No positive reaction was confirmed in this IHC with antigen-preabsorption (data not shown). After that, other slides from same specimen had been performed by same immunohistochemistry (TRPM8) without antigen-preabsorption. The IHC of tissue sections without antigen-preabsorption showed positive reaction. It could be suggested that anti-TRPM-8 rabbit polyclonal antibody, used in this study, had high specificity on its own antigen (TRPM8). However, western blot by using cells lines or other specimens should be performed to verify the specificity of TRPM8. In this study, we could not perform western blot analysis to rule out non-specific staining. Furthermore, non-immune rabbit serum (Dako, Glostrup, Denmark) was used as a negative control.

Briefly, after the blocking of endogenous peroxidase activity, antigen retrieval was conducted in $0.01 \mathrm{M}$ citrate buffer, $\mathrm{pH} 6.0$ at $120^{\circ} \mathrm{C}$ for $20 \mathrm{~min}$ in an autoclave. After rinsing in $0.01 \mathrm{M}$ phosphate-buffered saline (PBS), slides were incubated at $4^{\circ} \mathrm{C}$ for $6-8 \mathrm{~h}$ with the primary antibody. The streptavidin-biotin-peroxidase method was performed using an EnVision $^{\mathrm{TM}} /$ horseradish peroxidase-labeled anti-rabbit immunoglobulin antibody (Dako), and slides were incubated at room temperature for $1 \mathrm{~h}$. A positive reaction was detected as brown coloration with 3,3'-diaminobenzidine (DAB; Dojin Chemicals, Kumamoto, Japan). Sections were counterstained with hematoxylin.

TRPM8 ${ }^{+}$cells in reactive lymphoid tissues were estimated in different areas, such as the SYM/MZ, mantle zone, outer zone, light zone, dark zone, and interfollicular area (T-cell zone) in the tonsils; the MZ, mantle zone, light zone, dark zone, paracortical/interfollicular area, and medullary cords in the LN; and the dome, mantle zone, light zone, dark zone, and interfollicular area in the appendix. The identification of each zone in secondary lymphoid follicles was performed on serial sections for immunostaining using anti-TRPM8 and CD23

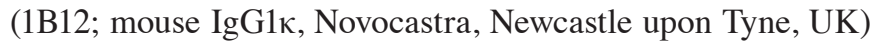
antibodies as described previously (Fig. 1A) (32).

In the estimation of the immunoreaction of TRPM8 in reactive lymphoid tissues, cells showing cell membrane and cytoplasmic staining equal to or greater than those of well-differentiated prostatic carcinoma cells and/or GC plasmablast-like cells in terms of intensity were judged as positive. At least 500 cells in each area of reactive lymphoid tissues were observed in 1-3 high-power-view fields (x400) and the percentage of TRPM8 ${ }^{+}$ cells among all cells in each area was calculated. Similarly, 500-1,000 neoplastic cells in mature B-cell neoplasms were observed in 1-3 high-power-view fields, and the frequency of $\mathrm{TRPM}^{+}$cells was estimated as score $0,<1 \%$ of positive cells; score 1, 1-25\%; score 2, 26-50\%; score 3, 51-75\%; and score $4,76-100 \%$. The frequencies of positive cells in reactive lymphoid tissues and B-cell neoplasms were evaluated by two independent observers (M.Y. and A.H.), and the mean values of their measurements were regarded as the results.

Double immunostaining in the tonsils. In the first step, tonsillar tissue sections were immunostained with 15 different types 

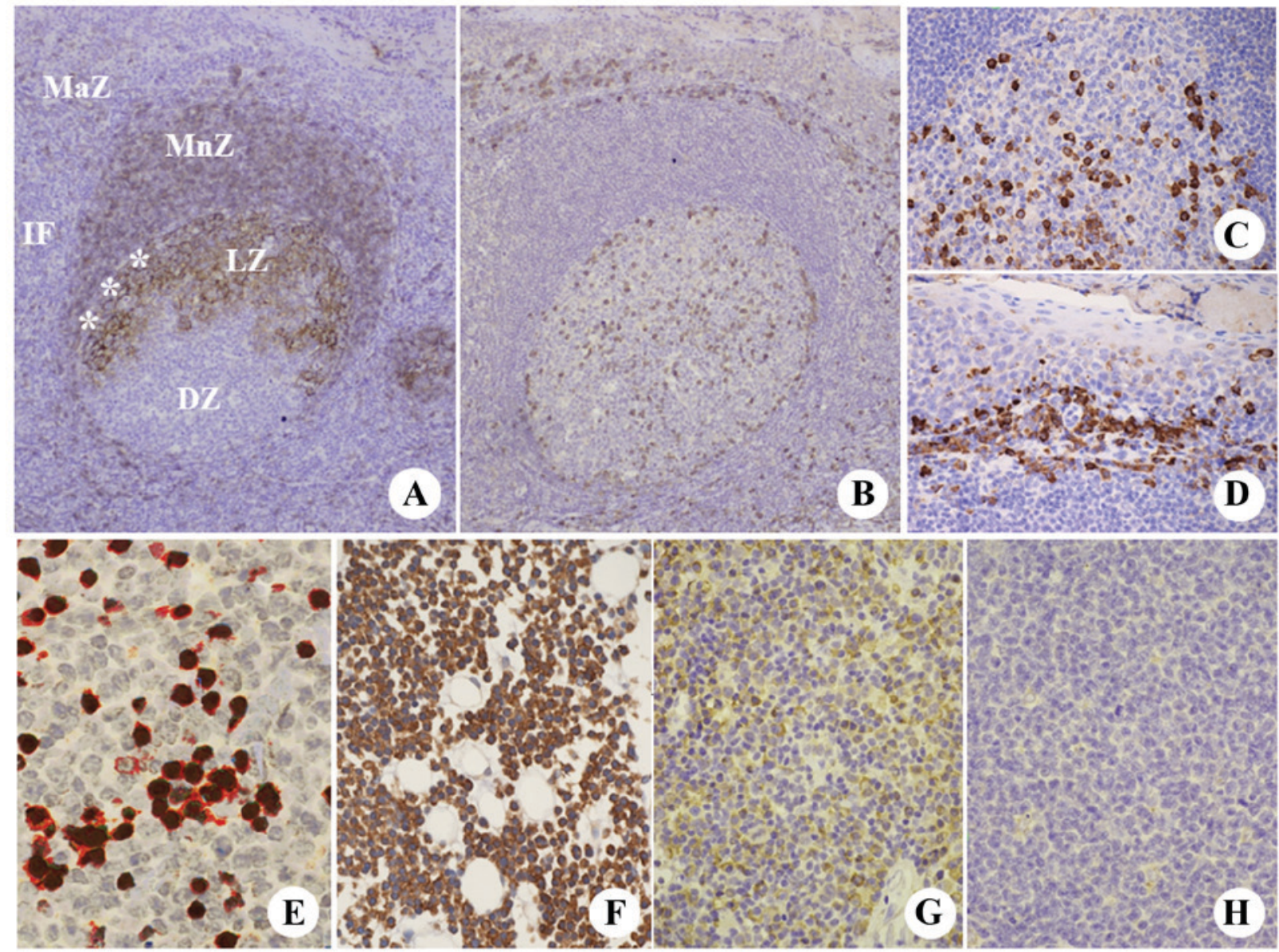

Figure 1. Immunohistochemistry of TRPM8 and lymphocyte markers in tonsils and mature B-cell neoplasms. (A) The CD23 immunostain recognizes four different zones of a tonsillar lymphoid follicle, namely, the MaZ, outer zone ("), LZ, and DZ. MZ: SYM/MZ; IF: Interfollicular area (x40). (B) The TRPM8 immunostain in the same lymphoid follicle as (A). There are many TRPM8 ${ }^{+}$cells in the light zone and SYM/MZ (x40). (C) TRPM8 ${ }^{+}$cells in the light zone of a tonsillar lymphoid follicle (x200). (D) TRPM8 ${ }^{+}$cells in SYM/MZ (x400). (E) Double immunostain of IRF4/MUM-1 and TRPM8 in the tonsillar germinal center using digital photomicrographs. The nuclei of IRF4/MUM-1 ${ }^{+}$cells are shown as blue in a digital photo. The same tissue section was immunostained with TRPM8 and IRF4/MUM-1+ TRPM8 $8^{+}$cells, shown as red in the photo. The first photo was overlaid with the second photo. IRF4/MUM-1 $1^{+}$TRPM8 ${ }^{+}$cells are recognized as cells having a black-colored nucleus and red-colored cytoplasm (x200). (F) TRPM8 ${ }^{+}$neoplastic cells in plasma cell myeloma; immunostaining score $=4$ (x200). (G) TRPM8 ${ }^{+}$cells in lymphoplasmacytic lymphoma; immunostaining score $=2$ (x200). (H) TRPM8 ${ }^{+}$cells in mantle cell lymphoma; immunostaining score $=0$ (x200). All sections were counterstained with hematoxylin. SYM, lymphoepithelial symbiosis; MZ, marginal zone; TRPM8, transient receptor potential melastatin 8; DZ, dark zonel LZ, light zone; MaZ, mantle zone; IF: Interfollicular area.

of lymphocyte markers to recognize B cells, $\mathrm{T}$ cells, natural killer cells, and plasma cells, such as antibodies against CD3 (PS1; mouse IgG2a), CD10 (56C6; mouse IgG1; both Nichirei, Tokyo, Japan), CD20 (L26; mouse IgG2к; Dako), CD23 (1B12; mouse IgG1к), CD38 (SPC32; mouse IgG1; both Novocastra), CD56 (1B6; mouse IgG1), CD79a (JCB117; mouse IgG1к), CD117 (Rabbit polyclonal; all Nichirei) CD138 (MI15; mouse

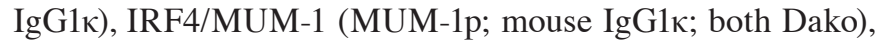
BCL6 (rabbit polyclonal; Santa Cruz Biotechnology, Inc., Dallas, TX, USA), paired box protein 5 (PAX5; 8F9; mouse IgG1א, Abgent, San Diego, CA, USA), programmed cell death 1 (PD1)/CD279 (NAT; mouse IgG1; Abcam, Cambridge, UK), BLIMP1 (3H2-E8; mouse IgG1; Thermo, Rockford, IL, USA), and transmembrane activator and calcium-signal modulating cyclophilin ligand interactor (TACI; 4976; mouse IgG, Santa Cruz Biotechnology, Inc.). A positive reaction was detected with the UltraTech HRP Streptavidin-Biotin Detection System (Beckman Coulter, Marseille, France) and DAB as a brown color. Digital photomicrographs were taken of high-power-view fields in the SYM/MZ and light zone, which contained a large number of TRPM8 ${ }^{+}$cells. In the second step, TRPM8 immunostaining was performed on the same tissue sections using the same method, and digital photomicrographs of the same fields as those in the first step were taken. Photos, bilayered by TRPM8 single immunostaining and TRPM8-lymphocyte marker double immunostaining, were created using image processing software (Adobe Photoshop Elements ${ }^{\circledast}$ 7.0, Adobe Systems, San Jose, CA, USA) (33). TRPM8 single-positive cells and double-positive cells in each of the 5 imaging photos of the SYM/MZ and light zone were counted and the ratio of double-positive cells to TRPM ${ }^{+}$cells was calculated.

$R T-P C R$. Frozen tissue specimens were obtained from 2 patients with $\mathrm{PCM}$, stored at $-80^{\circ} \mathrm{C}$ in a deep freezer, and a formalin-fixed paraffin-embedded tissue specimen with well-differentiated prostatic carcinoma was used as a positive control. In addition, formalin-fixed paraffin-embedded tissue specimens from PCM ( $n=5)$, FL $(n=3)$ and MCL $(n=2)$ were used. Undamaged mRNA was extracted from defrosted frozen cells by TRIzol ${ }^{\circledR}$ Reagent (Invitrogen; Thermo Fisher 
Table I. Expression of transient receptor potential melastatin 8 in reactive lymphoid tissues.

\begin{tabular}{lc}
\hline & $\begin{array}{c}\text { Positive cells/total cells } \\
\text { in each area }(\%)\end{array}$ \\
Tissues/areas & (mean \pm standard deviation) \\
\hline Tonsil & \\
SYM/marginal zone & $8.73 \pm 2.05^{\mathrm{e}}$ \\
Mantle zone & $0.20 \pm 0.13^{\mathrm{b}, \mathrm{e}}$ \\
Outer zone & $2.82 \pm 0.90$ \\
Light zone & $17.49 \pm 3.23$ \\
Dark zone & $1.05 \pm 0.50$ \\
Interfollicular area & $0.76 \pm 0.27^{\mathrm{f}}$ \\
Lymph node & \\
Marginal zone & $2.70 \pm 0.83$ \\
Mantle zone & $0.46 \pm 0.19^{\mathrm{c}, \mathrm{g}}$ \\
Light zone & $12.92 \pm 1.71^{\mathrm{g}}$ \\
Dark zone & $1.08 \pm 0.48$ \\
Paracortex/interfollicular area & $1.00 \pm 0.50$ \\
Medullary cord & $37.93 \pm 11.23^{\mathrm{c}}$ \\
Appendix & \\
Dome & $5.75 \pm 2.15^{\mathrm{h}}$ \\
Mantle zone & $0.37 \pm 0.19^{\mathrm{d}, \mathrm{h}}$ \\
Light zone & $9.34 \pm 2.18^{\mathrm{d}}$ \\
Dark zone & $0.99 \pm 0.23$ \\
Interfollicular area & $0.99 \pm 0.41$ \\
\hline
\end{tabular}

SYM, lymphoepithelial symbiosis. ${ }^{\mathrm{a}} \mathrm{P}<0.01$ by Kruskal-Wallis test, ${ }^{\mathrm{b}} \mathrm{P}<0.01$ mantle zone vs. light zone in tonsil, ${ }^{\mathrm{c}} \mathrm{P}<0.01$ medullary cord vs. mantle zone in lymph node, ${ }^{\mathrm{d}} \mathrm{P}<0.01$ mantle zone vs. light zone in appendix, ${ }^{e} \mathrm{P}<0.05 \mathrm{SYM} /$ marginal zone vs. mantle zone in tonsil, ${ }^{\mathrm{f}} \mathrm{P}<0.05$ light zone vs. interfollicular area in tonsil, ${ }^{\mathrm{g}} \mathrm{P}<0.05$ mantle zone vs. light zone in lymph node, ${ }^{\mathrm{h}} \mathrm{P}<0.05$ dome vs. mantle zone in appendix, respectively by Scheffé's multiple comparison test.

Scientific, Inc., Waltham, MA, USA). We used WaxFreeTM RNA (TrimGen, Sparks Glencoe, MD, USA) by which a sufficient volume of undamaged mRNA was successfully extracted from formalin-fixed paraffin-embedded prostatic carcinoma tissue specimens (34).

Extracted mRNA refined with water saturation phenol/chloroform was used for RT-PCR with the PrimeScript II 1st strand cDNA Synthesis kit (Takara Bio, Otsu, Japan). We used primer pairs designed by OriGene Technologies (Rockville, MD, USA) and produced by Fasmac (Atsugi, Japan); primer sequences were as follows: Sense, 5'-CTGGTTGCGAACTTCCGAAGA G-3' and antisense, 5'-GGTGCCGAGTAATAGGAGACAC-3'. The primary sequences for $\beta$-actin were: Sense, 5'-CAGAGC AAGAGAGGCATCCT-3' and antisense, 5'-ACGTACATG GCTGGGGTG-3', and the primary sequences for GAPDH were sense, 5'-GCACCGTCAAGGCTGAGAAC-3' and antisense, 5'-TGGTGAAGACGCCAGTGGA-3'. A mixture of $2 \mu 1$ of primer pairs, $20 \mu \mathrm{l}$ of $\mathrm{dH}_{2} \mathrm{O}, 3 \mu \mathrm{l}$ of synthesized cDNA, and $25 \mu$ l of the EmeraldAmp ${ }^{\mathrm{TM}}$ PCR Master Mix (Takara Bio) was added to a $0.2-\mathrm{ml}$ microtube. The mixture was heat-denatured at $94^{\circ} \mathrm{C}$ for $4 \mathrm{~min}$ on a thermal cycler (Veriti ${ }^{\mathrm{TM}}$; Applied
Table II. Frequency of the co-expression of lymphocyte markers on TRPM8-positive cells in the reactive tonsillar germinal center and SYM/marginal zone by double immunostaining.

Frequency of co-expression of lymphocyte markers on TRPM $8^{+}$cells $(\%)$ (mean \pm standard deviation)

\begin{tabular}{lcc} 
Antibodies & Germinal center & SYM/marginal zone \\
\hline CD3 & $0.00 \pm 0.00$ & $0.00 \pm 0.00$ \\
CD10 & $11.14 \pm 0.05$ & $5.87 \pm 0.12$ \\
CD20 & $17.82 \pm 3.70$ & $8.52 \pm 4.95$ \\
CD23 & $0.00 \pm 0.00$ & $0.00 \pm 0.00$ \\
CD38 & $72.60 \pm 15.46$ & $74.87 \pm 10.71$ \\
CD56 & $0.00 \pm 0.00$ & $0.00 \pm 0.00$ \\
CD79a & $59.57 \pm 2.76$ & $60.41 \pm 20.15$ \\
CD117 & $0.00 \pm 0.00$ & $0.00 \pm 0.00$ \\
CD138 & $32.29 \pm 5.61$ & $52.28 \pm 18.51$ \\
IRF4/MUM-1 & $69.12 \pm 23.42$ & $58.77 \pm 12.95$ \\
BCL6 & $69.75 \pm 18.35$ & $47.73 \pm 10.45$ \\
PAX5 & $0.74 \pm 0.65$ & $4.09 \pm 3.55$ \\
PD1 & $0.00 \pm 0.00$ & $0.00 \pm 0.00$ \\
BLIMP1 & $0.00 \pm 0.00$ & $0.00 \pm 0.00$ \\
TACI & $62.54 \pm 1.44$ & $71.21 \pm 25.85$
\end{tabular}

IRF4/MUM-1, interferon-regulating factor 4/multiple myeloma oncogene 1; BCL6, B-cell CLL/lymphoma 6; PAX5, paired box protein 5; PD1, programmed cell death 1; BLIMP1, B lymphocyte maturation protein-1; TACI, transmembrane activator and calcium-signal modulating cyclophilin ligand interactor; TRPM8, transient receptor potential melastatin 8 ; SYM, lymphoepithelial symbiosis; CD, cluster of differentiation.

Biosystems; Thermo Fisher Scientific, Inc.), at $94^{\circ} \mathrm{C}$ for 2 min (50 cycles), at $57^{\circ} \mathrm{C}$ for $2 \mathrm{~min}$, at $72^{\circ} \mathrm{C}$ for $2 \mathrm{~min}$, and finally at $72^{\circ} \mathrm{C}$ for 6 min. PCR products were stored at $4^{\circ} \mathrm{C}$ until electrophoresis. We used a $4.0 \%$ agarose gel (NuSieve ${ }^{\circledR} 3-1$ Agarose, Lonza, Rockland, ME, USA), 1xTAE buffer, and ethidium bromide for electrophoresis. $\beta$-actin (227 bp) and GAPDH (138 bp) primers were used as housekeeping mRNA for internal control (normalization of RT-PCR) and distilled water was used as a negative control instead of reverse transcriptase.

Statistical analysis. Dr. SPSS II software for Windows was used in statistical analyses. Spearman's correlation coefficient was used to test the interobserver correlation of the first and second observers. We performed the Kruskal-Wallis test to analyze the TRPM8-positive ratio in reactive lymphoid tissues and the scores of the TRPM8-positive ratio of mature B-cell neoplasms, and when cases were considered to be significant, we performed Scheffé's multiple comparison tests. Differences with $\mathrm{P}<0.05$ were considered to be significant in each case.

\section{Results}

Localization of TRPM8+ cells in reactive lymphoid tissues. There were significantly more TRPM $8^{+}$cells in the SYM/MZ 
Table III. Expression of TRPM8 in mature B-cell neoplasms.

Types of lymphomas (number of cases)

TRPM8 scores (mean \pm standard deviation $)^{\mathrm{a}}$

Small lymphocytic lymphoma $(n=3)$

$0.00 \pm 0.00^{\circ}$

Lymphoplasmacytic lymphoma $(n=4)$

$2.25 \pm 0.50$

Plasma cell neoplasm $(n=16)$

$4.00 \pm 0.00^{\mathrm{b}, \mathrm{d}, \mathrm{e}}$

Extranodal marginal zone lymphoma $(n=5)$

$2.20 \pm 0.45$

Follicular lymphoma $(\mathrm{n}=5)$

$0.00 \pm 0.00^{\mathrm{b}}$

Mantle cell lymphoma $(n=3)$

$0.00 \pm 0.00^{\mathrm{d}}$

Diffuse large B-cell lymphoma $(n=18)$

$0.72 \pm 0.83^{\mathrm{e}}$

Germinal center B-cell-like $(n=7)$

$0.71 \pm 0.95$

Non-germinal center B-cell-like $(n=11)$

$0.73 \pm 0.79$

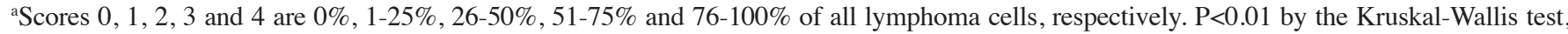
${ }^{\mathrm{b}} \mathrm{P}<0.01$ plasma cell neoplasm vs. follicular lymphoma, ${ }^{\mathrm{C}} \mathrm{P}<0.05$ plasma cell neoplasm vs. small lymphocytic lymphoma, ${ }^{\mathrm{d}} \mathrm{P}<0.05$ plasma cell neoplasm vs. mantle cell lymphoma, ${ }^{\mathrm{e}} \mathrm{P}<0.01$ plasma cell neoplasm vs. diffuse large B-cell lymphoma, by Scheffé's multiple comparison test. TRPM8, transient receptor potential melastatin 8.

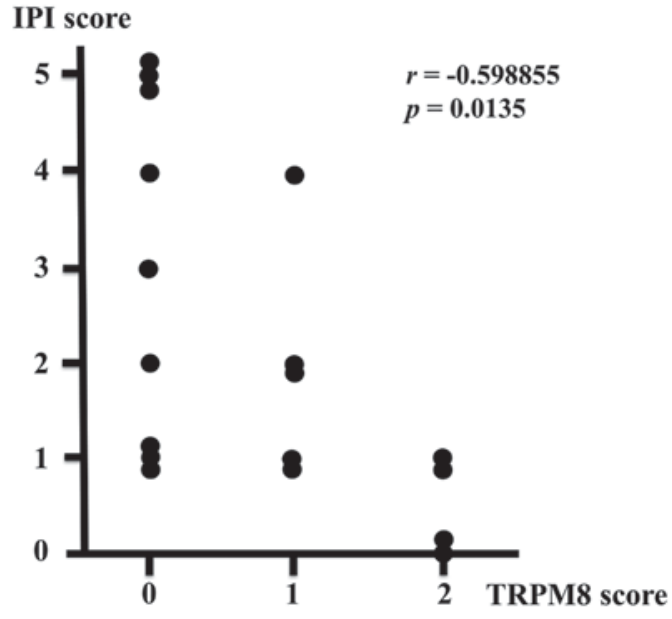

Figure 2. Relationship between IPI and TRPM8 scores. A close relationship was found between both scores $(r=-0.598855, \mathrm{P}=0.0135)$. TRPM8, transient receptor potential melastatin 8 ; IPI, international prognostic index.

and light zone (Fig. 1B-D) than in the mantle zone and interfollicular area of the tonsils (Table I). In the LN, more TRPM8 ${ }^{+}$ cells were observed in the light zone and medullary cord in contrast to the mantle zone. Similarly, more TRPM $8^{+}$cells were found in the light zone and dome in contrast to the mantle zone in the appendix. Positive cells in the GC had morphological features similar to those of plasmablasts, while those in the SYM/MZ, medullary cord, and dome were morphologically similar to plasma cells.

In addition, we confirmed TRPM $8^{+}$cancer cells in prostatic carcinoma tissues as positive controls and no positive cells in negative controls using non-immune rabbit serum instead of the primary antibody.

Double immunohistochemistry of the tonsils. TRPM8+ cells frequently co-expressed CD38, CD79a, IRF4/MUM-1, BCL6 (Fig. 1E), and TACI in the GC, and CD38,CD79a, CD138, IRF4/MUM-1, BCL6, and TACI in the SYM/MZ (Table II). On the other hand, TRPM $8^{+}$cells less frequently expressed
CD10, CD20, and PAX5, and did not express CD3, CD23, CD56, CD117, PD1, or BLIMP1.

Expression of TRPM8 in mature B-cell neoplasms. In all types of PCN, such as MGUS, PCM, and extraosseous plasmacytoma, the immunostaining score was $4(4.0 \pm 0.00)$, revealing that most neoplastic cells were TRPM8 ${ }^{+}$(Fig. 1F; Table III). No significant differences were observed in immunostaining scores between the $\mathrm{IgG}$ and IgA types of the PCM. The proportion of TRPM8 ${ }^{+}$cells/neoplastic cells of LPL (Fig. 1G) and MALT lymphoma was approximately 26-50\%. The immunostaining score of DLBCL was low $(<25 \%)$. Furthermore, no significant difference was observed in immunostaining scores between the GCB subtype and non-GCB subtype of DLBCL. Neither SLL, FL, nor MCL contained TRPM8+ neoplastic cells (Fig. 1H). In all lymphomas, TRPM8 ${ }^{+}$cells had an abundant cytoplasm and eccentric nucleus, resembling plasmablasts and PCs.

In the judgment of TRPM8 ${ }^{+}$cells in reactive lymphoid tissues and mature B-cell neoplasms, a good correlation was found between two observers; the interobserver correlations of the first and second observers were $r=0.952(\mathrm{P}<0.001)$ in the tonsils $(\mathrm{n}=35), r=0.989(\mathrm{P}<0.001)$ in the $\mathrm{LN}(\mathrm{n}=35), r=0.938$ $(\mathrm{P}<0.001)$ in the appendix $(\mathrm{n}=36)$, and $r=0.974(\mathrm{P}<0.001)$ in mature B-cell neoplasms $(n=54)$.

Spearman's rank correlation coefficient in our DLBCL patients revealed a close relationship between TRPM8 and international prognostic index (IPI) scores $(\mathrm{P}=0.0135$, $r=-0.599)$, revealing that DLBCL patients with lower TRPM8 scores have higher IPI scores; however, the number of cases was small (Fig. 2).

$R T$-PCR. We recognized a positive band identical to TRPM8 mRNA at a length of $100 \mathrm{bp}$ in a case of well-differentiated prostatic carcinoma (positive control), as well as in cases of PCM, but not in the negative control (Fig. 3A). In addition, positive band of TRPM8 was recognized in a case of PCM ( 1 out of 5 cases), but not in FL (n=3) and MCL (n=2) using FFPE specimens (Fig. 3B). 

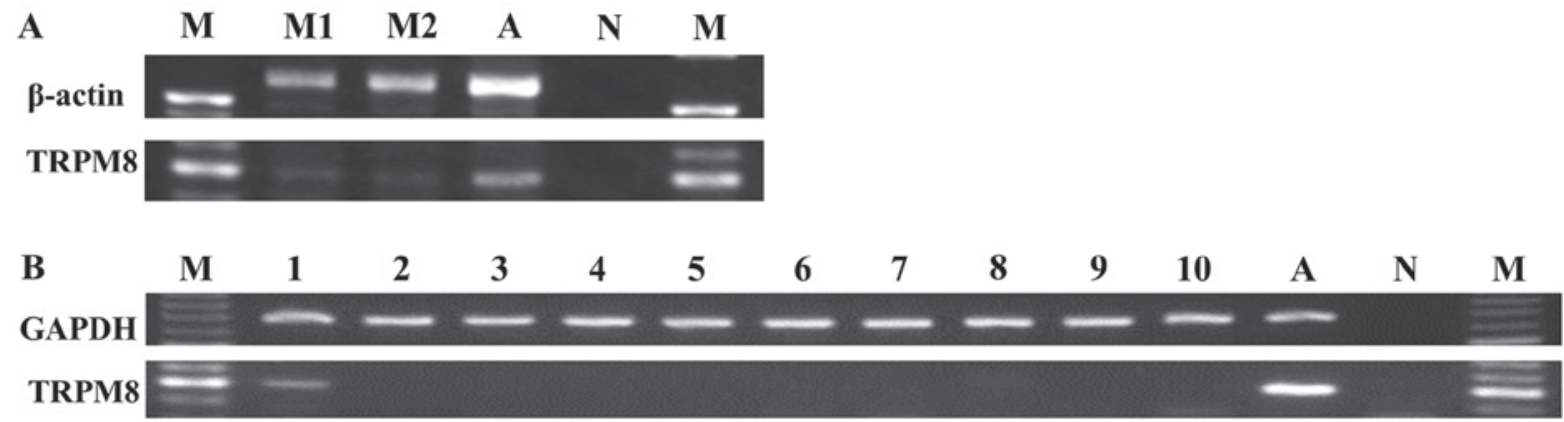

Figure 3. RT-PCR of TRPM8 mRNA in plasma cell myeloma, follicular lymphoma and mantle cell lymphoma. (A) A positive band of 100 bp in length for TRPM8 mRNA was found in two cases of plasma cell myeloma (M1 \& M2) using frozen tissue specimens. (B) A positive band of 100 bp in length for TRPM8 mRNA was found in one case of plasma cell myeloma $(1-5 ; n=5)$, but not in follicular lymphoma $(6,7$ and 8 ; $n=3)$ and mantle cell lymphoma $(9,10 ; n=2)$ using FFPE tissue specimens. $(M)$ Molecular markers, $(N)$ negative control, $(A)$ well-differentiated prostatic carcinoma as a positive control. TRPM8, transient receptor potential melastatin 8 ; RT-PCR, reverse transcription polymerase chain reaction.

\section{Discussion}

TRPM8 is a thermoreceptor that is sensitive to cold stimuli below $28^{\circ} \mathrm{C}$ and chemicals, such as menthol and icilin, that induce the sensation of cold $(35,36)$. It localizes on the cell surface membrane and endoplasmic reticulum (ER). It is expressed in the male urogenital apparatus, such as the prostate gland, testis, and urinary bladder, as well as the liver and nervous system among normal organs, and is found in some malignant tumors, including androgen-dependent prostate cancer, pancreatic cancer, breast cancer, and melanoma (13,14,21-26). TRPM8 regulates the proliferation and apoptosis of prostatic epithelial cells, and cell death is induced by an inflow of $\mathrm{Ca}^{2+}$ into cells via TRPM8 $(13,14)$. A previous study reported that murine B cells express TRPC1, C2, C6, V2, V4, M2, M4, M5, and M7 among the TRP superfamily (27).

To the best of our knowledge, this is the first study to demonstrate the expression of TRPM8 in reactive lymphoid tissues and mature B-cell neoplasms. In contrast to the mantle zone, the light zone had many TRPM $8^{+}$cells in all reactive lymphoid tissues (the tonsils, LN, and appendix). In addition, there were many TRPM $8^{+}$cells in the tonsillar SYM/MZ, LN medullary cord, and appendiceal dome. The morphology of positive cells in the light zone was similar to that of plasmablasts, and those in the SYM/MZ, medullary cord, and dome were carried out with PCs. In order to confirm these results, we performed double immunostaining and revealed that TRPM $8^{+}$ cells in the follicular light zone and SYM/MZ often co-express CD38 (72 and 74\%), CD79a (59 and 60\%), IRF4/MUM-1 (69 and 58\%), BCL6 (69 and 47\%), TACI (62 and 71\%), and sometimes CD138 (32 and 52\%).

Jego et al (1) reported that the immunophenotypes of activated $\mathrm{B}$ cells, pre-plasmablasts, plasmablasts, and early $\mathrm{PCs}$ are $\mathrm{CD} 20^{+} \mathrm{CD} 38^{ \pm} \mathrm{CD} 138^{-}, \mathrm{CD} 20^{ \pm} \mathrm{CD} 38^{+} \mathrm{CD} 138^{-}$, $\mathrm{CD} 20^{-} \mathrm{CD} 38^{+++} \mathrm{CD} 138^{-}$, and $\mathrm{CD} 20^{-} \mathrm{CD} 38^{+++} \mathrm{CD} 138^{++}$, respectively. Harada et al (2) demonstrated that normal $\mathrm{PCs}$ are $\mathrm{CD} 38^{++} \mathrm{CD} 56^{-\mathrm{CD} 19^{+}}$by two-color flow cytometry. Thus, late PCs may be $\mathrm{CD} 19^{+} \mathrm{CD} 20{ }^{-} \mathrm{CD} 38^{+++} \mathrm{CD} 138^{+++}$. $\mathrm{CD} 79$ a is widely expressed from GC-B cells to PCs (4), IRF4/MUM-1 is found on $\mathrm{CD} 20^{+} \mathrm{CD} 38^{+} \mathrm{B}$ cells (the intermediate of $\mathrm{B}$-cell lymphoma 6 protein $(\mathrm{BCL} 6)^{+} \mathrm{B}$ cells and $\mathrm{CD} 138^{+} \mathrm{B}$ cells) in the follicular light zone (37), TACI is more likely to be expressed on late-stage B cells, such as plasmablasts and
PCs $(34,38)$, and PAX5 is a transcription factor indispensable for B-cell differentiation, but disappears from PCs (4). In the present study, TRPM $8^{+}$cells were negative for CD56 and CD117 appearing on PCN (32), and for PD1 appearing on follicular helper T-cells (39). Taken together, the vast majority of TRPM8 ${ }^{+}$cells in the follicular light zone may be compatible with pre-plasmablasts and/or plasmablasts and in the SYM/MZ with early and/or late PCs, indicating that TRPM8 may be expressed from pre-plasmablasts to late PCs Fig. 4), available as a potential supplementary plasma cell marker. CD38 expression levels significantly decrease in $80 \%$ of all myeloma cases, plasma cells expressing low levels of CD138 have frequently been reported, and CD138- plasma cells are present in the peripheral blood (3). As shown in Fig. 4, TRPM8 detected CD138 plasmablasts and CD38 or CD138- pre-plasmablasts.

Based on the WHO classification, B-cell neoplasms have been further classified into precursor B-cell neoplasms, pre-GC neoplasms, GC neoplasms, and post-GC neoplasms (4). We examined TRPM8 immunostaining in MCL as pre-GC neoplasms, FL and DLBCL as GC neoplasms, and SLL, MALT lymphoma, LPL, DLBCL, and $\mathrm{PCN}$ as post-GC neoplasms. As a result, all $\mathrm{PCN}(\mathrm{n}=16)$ were score 4 (76\%), most LPL and MALT lymphomas score 2, and DLBCL score $0-1$. The RT-PCR analysis conducted in the present study also confirmed TRPM8 mRNA expression in PCM tissues, not in FL and MCL. RT-PCR analysis on FFPE specimens of PCN (bone marrow aspirate) showed positive reaction in only one case. It may be because mass number of red blood cells in bone marrow may inhibit the RT-PCR analysis $(40,41)$. Siebolts et al examined microRNAs on various tissue by quantitative PCR and showed little microRNA in bone marrow comparing with other tissues (42).

On the other hand, there were no TRPM $8^{+}$neoplastic cells in SLL, FL, or MCL. Therefore, TRPM8 ${ }^{+}$cells appear to localize in some GC neoplasms and most post-GC neoplasms, but not in pre-GC neoplasms and most GC neoplasms, further indicating that TRPM8 has potential as a marker to identify reactive plasmablasts/PCs and mature B-cell neoplasms that are likely to differentiate into PCs in a practical differential diagnosis using formalin-fixed and paraffin-embedded tissue sections. 

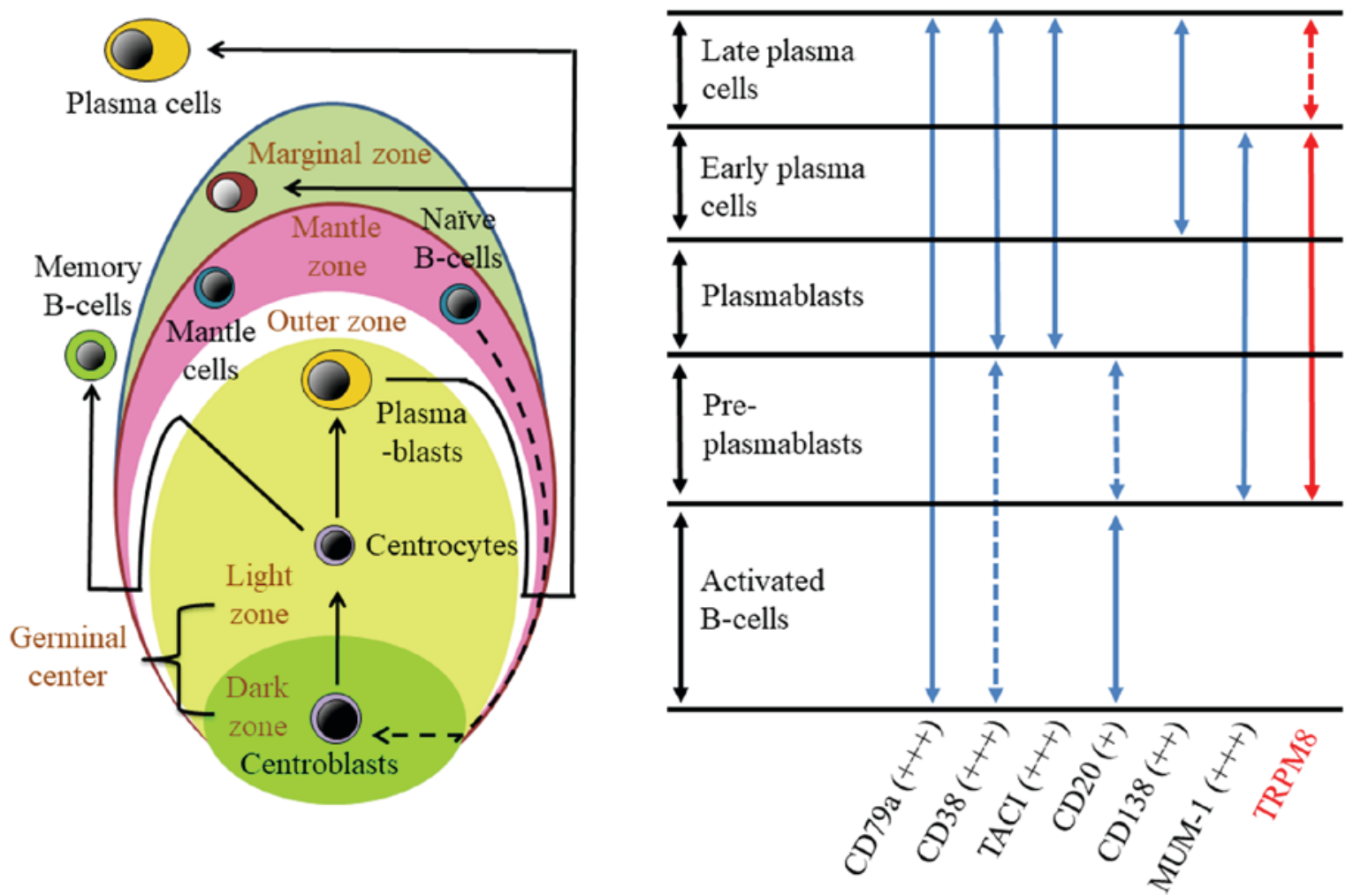

Figure 4. Scheme showing the relationship between normal B-cell differentiation (left $)$ and markers including TRPM8 (right). Activated B cells, pre-plasmablasts, and plasmablasts in the germinal center are $\mathrm{CD} 20^{+} \mathrm{CD} 38^{ \pm} \mathrm{CD} 79 \mathrm{a}^{+}, \mathrm{CD} 20^{ \pm} \mathrm{CD} 38^{ \pm} \mathrm{CD} 79 \mathrm{a}^{+} \mathrm{IRF} 4 / \mathrm{MUM}-1^{+}$, and CD $38^{+} \mathrm{CD} 79 \mathrm{a}^{+} \mathrm{TACI}{ }^{+} \mathrm{IRF} 4 / \mathrm{MUM}-1^{+}$, respectively Further differentiated early and late plasma cells in the extrafollicular area are $\mathrm{CD} 38^{+} \mathrm{CD} 79 \mathrm{a}^{+} \mathrm{CD} 138^{+} \mathrm{TACI}^{+} \mathrm{IRF} 4 / \mathrm{MUM}^{+} 1^{+}$and $\mathrm{CD} 38^{+} \mathrm{CD} 79 \mathrm{a}^{+} \mathrm{CD} 138^{+} \mathrm{TACI}{ }^{+}$, respectively. The present study demonstrated that TRPM8 is expressed on cells differentiating from pre-plasmablasts to late plasma cells. TACI (+): 10-30\%, $(++) ; 30-50 \%,(+++) ;>50 \%$ of the co-expression ratio of lymphocyte markers on TRPM8 ${ }^{+}$cells. Dotted arrows: Often positive. TRPM8, transient receptor potential melastatin 8; CD, cluster of differentiation; MUM, multiple myeloma oncogene; TACI, transmembrane activator and calcium-signal modulating cyclophilin ligand interactor.

TRPM8 is up-regulated in androgen-dependent prostate cancer, and affects the growth inhibition and dedifferentiation of neoplastic cells $(13,14,21-26)$. TRPM8 was defined as an effective diagnostic and prognostic marker in prostate cancer $(13,14,21)$. The present study also revealed a close relationship between TRPM8 and the IPI scores of DLBCL $(\mathrm{P}=0.0135, r=-0.599)$, demonstrating that DLBCL patients with lower TRPM8 scores have a worse prognosis; however, the number of cases tested was small.

Previous studies reported that TRPM8 facilitates the inflow of $\mathrm{Ca}^{2+}$ and $\mathrm{Na}^{+}$across the plasma membrane and may mediate the release of $\mathrm{Ca}^{2+}$ from the ER because some TRPM8 is expressed in the ER as well as the plasma membrane $(43,44)$. Tartakoff and Vassalli (45) showed that $\mathrm{Na}^{+}$and $\mathrm{Ca}^{2+}$ homeostasis influences immunoglobulin secretion in plasma cells. Thus, TRPM8 may have a link with immunoglobulin secretion in plasma cells. Furthermore, the extracellular domain GLMKYIGEV region of TRPM8 may activate cytotoxic T-lymphocytes, which play a role in cell destruction, suggesting that TRPM8 has potential as an immunotherapeutic target (46). However, the precise function of TRPM8 expressed on pre-plasmablasts, plasmablasts, PCs, and neoplastic cells, such as PCN, currently remains unclear and, thus, future studies including cell culture and/or mouse study to detect the influencing effect of TRPM8 on plasma cell to produce antibodies in inflammation and in cancer surrounding environment, and influencing factors of TRPM8 on worst prognosis of malignancy, are needed.
The present study is the first to demonstrate the expression of TRPM8 in reactive lymphoid tissues and mature B-cell neoplasms, revealing that TRPM8 is frequently expressed on pre-plasmablasts, plasmablasts, $\mathrm{PCs}$, and mature B-cell lymphomas that are likely to differentiate into PCs. TRPM8, as one of the plasmacytic differentiation markers, may serve as a useful supplementary tool in the differential diagnosis of mature B-cell neoplasms.

\section{Acknowledgements}

The authors would like to thank Mr. Hitoshi Suzuki, Ms. Kumiko Abe and Ms. Hiromi Murata of the Department of Diagnostic Pathology, Yamagata University Faculty of Medicine, for their technical support.

\section{Funding}

The present study was supported by Grants-in-Aid for Scientific Research (grant no. 17K08736) by the Ministry of Education, Culture, Sports, Science and Technology in Japan (https://www.jsps.go.jp/english/e-grants) and the Yamagata University Faculty of Medicine.

\section{Availability of data and materials}

The datasets used and/or analyzed during the current study are available from the corresponding author on reasonable request. 


\section{Authors' contributions}

AH was involved in study conception, study design, experimentation, data analysis and manuscript writing. NYA was involved in study conception, study design, experimentation, data analysis and manuscript revision. RO and HM were involved in experimentation and data analysis. AN and TK were involved in study conception and experimentation. KI and JF were involved in study conception and reviewed the manuscript. MY was involved in study conception, study design, data analysis, manuscript writing and manuscript revision. All authors read and approved the manuscript.

\section{Ethics approval and consent to participate}

Written informed consent was obtained from each patient. The use of tissues and clinical information study was approved by the Ethics Committee of Yamagata University School of Medicine.

\section{Patient consent for publication}

Written informed consent was obtained from each patient.

\section{Competing interests}

The authors declare that they have no competing interests.

\section{References}

1. Jego G, Bataille R and Pellat-Deceunynck C: Interleukin-6 is a growth factor for nonmalignant human plasmablasts. Blood 97: 1817-1822, 2001.

2. Harada H, Kawano MM, Huang N, Harada Y, Iwato K, Tanabe O, Tanaka H, Sakai A, Asaoku H and Kuramoto A: Phenotypic difference of normal plasma cells from mature myeloma cells. Blood 81: 2658-2663, 1993.

3. Paiva B, Almeida J, Pérez-Andrés M, Mateo G, López A, Rasillo A, Vídriales MB, López-Berges MC, Miguel JF and Orfao A: Utility of flow cytometry immunophenotyping in multiple myeloma and other clonal plasma cell-related disorders. Cytometry B Clin Cytom 78: 239-252, 2010.

4. Jaffe ES, Campo E, Harris NL, Pileri SA, Stein H and Swerdlow SH (eds): Introduction and overview of the classification of lymphoid neoplasms. In: WHO Classification of Tumours of Haematopoietic and Lymphoid Tissues, Revised 4th edition, Swerdlow SH, Campo E, Harris NL, Jaffe ES, Pileri SA, Stein H, Thiele J, Arber DA, Hasserjian RP, Le Beau MM, Orazi A, Siebert R. International Agency for Research on Cancer (IARC), Lyon, pp190-198, 2017.

5. McKenna RW, Kyle RA, Kuehl WM, Harris NL, Coupland RW, Fend F (eds): Plasma cell neoplasms. In: WHO Classification of Tumours of Haematopoietic and Lymphoid Tissues, Revised 4th edition, Swerdlow SH, Campo E, Harris NL, Jaffe ES, Pileri SA, Stein H, Thiele J, Arber DA, Hasserjian RP, Le Beau MM, Orazi A, Siebert R. International Agency for Research on Cancer (IARC), Lyon, pp241-258, 2017.

6. Raja KR, Kovarova L and Hajek R: Review of phenotypic markers used in flow cytometric analysis of MGUS and MM, and applicability of flow cytometry in other plasma cell disorders. $\mathrm{Br}$ J Haematol 149: 334-351, 2010.

7. Rawstron AC, Orfao A, Beksac M, Bezdickova L, Brooimans RA, Bumbea H, Dalva K, Fuhler G, Gratama J, Hose D, et al: Report of the European Myeloma Network on multiparametric flow cytometry in multiple myeloma and related disorders Haematologica 93: 431-438, 2008.

8. Bataille R, Jégo G, Robillard N, Barillé-Nion S, Harousseau JL, Moreau P, Amiot M and Pellat-Deceunynck C: The phenotype of normal, reactive and malignant plasma cells. Identification of 'many and multiple myelomas' and of new targets for myeloma therapy. Haematologica 91: 1234-1240, 2006.

9. Li H: TRP channel classification. Adv Exp Med Biol 976: 1-8, 2017.
10. Yin Y, Wu M,Zubcevic L, Borschel WF, Lander GC and Lee SY: Structure of the cold- and menthol-sensing ion channel TRPM8. Science 359: 237-241, 2018

11. Seebacher F and Little AG: Plasticity of performance curves can buffer reaction rates from body temperature variation in active endotherms. Front Physiol 8: 575, 2017.

12. Tsavaler L, Shapero MH, Morkowski S and Laus R: Trp-p8, a novel prostate-specific gene, is up-regulated in prostate cancer and other malignancies and shares high homology with transient receptor potential calcium channel proteins. Cancer Res 61: 3760-3769, 2001.

13. Grolez GP and Gkika D: TRPM8 puts the chill on prostate cancer. Pharmaceuticals (Basel) 9: pii: E44, 2016.

14. Asuthkar S, Demirkhanyan L, Mueting SR, Cohen A and Zakharian E: High-throughput proteome analysis reveals targeted TRPM8 degradation in prostate cancer. Oncotarget 8: 12877-12890, 2017.

15. Carrasquel-Ursulaez W, Moldenhauer H, Castillo JP, Latorre R and Alvarez O: Biophysical analysis of thermosensitive TRP channels with a special focus on the cold receptor TRPM8. Temperature (Austin) 2: 188-200, 2015.

16. Koh WU, Choi SS, Kim JH, Yoon HJ, Ahn HS, Lee SK, Leem JG, Song JG and Shin JW: The preventive effect of resiniferatoxin on the development of cold hypersensitivity induced by spinal nerve ligation: Involvement of TRPM8. BMC Neurosci 17: 38, 2016.

17. Borowiec AS, Sion B, Chalmel F, D Rolland A, Lemonnier L, De Clerck T, Bokhobza A, Derouiche S, Dewailly E, Slomianny $\mathrm{C}$, et al: Cold/menthol TRPM8 receptors initiate the cold-shock response and protect germ cells from cold-shock-induced oxidation. FASEB J 30: 3155-3170, 2016.

18. Pérez de Vega MJ, Gómez-Monterrey I, Ferrer-Montiel A and González-Muñiz R: Transient receptor potential melastatin 8 channel (TRPM8) modulation: Cool entryway for treating pain and cancer. J Med Chem 59: 10006-10029, 2016.

19. Pan Y, Thapa D, Baldissera L Jr, Argunhan F, Aubdool AA and Brain SD: Relevance of TRPA1 and TRPM8 channels as vascular sensors of cold in the cutaneous microvasculature. Pflugers Arch 470: 779-786, 2018.

20. Fujita T, Liu Y, Higashitsuji H, Itoh K, Shibasaki K, Fujita J and Nishiyama H: Involvement of TRPV3 and TRPM8 ion channel proteins in induction of mammalian cold-inducible proteins. Biochem Biophys Res Commun 495: 935-940, 2018.

21. Yee NS: Roles of TRPM8 ion channels in cancer: Proliferation, survival, and invasion. Cancers (Basel) 7: 2134-2146, 2015.

22. Yee NS: TRPM8 ion channels as potential cancer biomarker and target in pancreatic cancer. Adv Protein Chem Struct Biol 104: 127-155, 2016.

23. Liu Z, Wu H, Wei Z, Wang X, Shen P, Wang S, Wang A, Chen W and Lu Y: TRPM8: A potential target for cancer treatment. J Cancer Res Clin Oncol 142: 1871-1881, 2016.

24. Ceylan GG, Önalan EE, Kuloğlu T, Aydoğ G, Keleş İ, Tonyali Ş and Ceylan C: Potential role of melastatin-related transient receptor potential cation channel subfamily $M$ gene expression in the pathogenesis of urinary bladder cancer. Oncol Lett 12: 5235-5239, 2016.

25. Ulăreanu R, Chiriţoiu G, Cojocaru F, Deftu A, Ristoiu V, Stănică L, Mihăilescu DF and Cucu D: N-glycosylation of the transient receptor potential melastatin 8 channel is altered in pancreatic cancer cells. Tumour Biol 39: 1010428317720940, 2017.

26. Burke RC, Bardet SM, Carr L, Romanenko S, Arnaud-Cormos D, Leveque P and O'Connor RP: Nanosecond pulsed electric fields depolarize transmembrane potential via voltage-gated $\mathrm{K}^{+}, \mathrm{Ca}^{2+}$ and TRPM8 channels in U87 glioblastoma cells. Biochim Biophys Acta 1859: 2040-2050, 2017.

27. Inada $\mathrm{H}$, Iida $\mathrm{T}$ and Tominaga $\mathrm{M}$ : Different expression patterns of TRP genes in murine B and T lymphocytes. Biochem Biophys Res Commun 350: 762-767, 2006.

28. Schwarz EC, Wolfs MJ, Tonner S, Wenning AS, Quintana A, Griesemer D and Hoth M: TRP channels in lymphocytes. Handb Exp Pharmacol 179: 445-456, 2007.

29. Zierler S, Hampe S and Nadolni W: TRPM channels as potential therapeutic targets against pro-inflammatory diseases. Cell Calcium 67: 105-115, 2017.

30. Gascoyne RD, Chan JKC, Campo E, Rosenwald A, Jaffe ES, Stein H, Chan WC, Swerdlow SH (eds): Diffuse large B-cell lymphoma, NOS. In: WHO Classification of Tumours of Haematopoietic and Lymphoid Tissues, Revised 4th edition, Swerdlow SH, Campo E, Harris NL, Jaffe ES, Pileri SA, Stein H, Thiele J, Arber DA, Hasserjian RP, Le Beau MM, Orazi A, Siebert R. International Agency for Research on Cancer (IARC), Lyon, pp291-297, 2017. 
31. El Karim IA, Linden GJ, Curtis TM, About I, McGahon MK Irwin CR and Lundy FT: Human odontoblasts express functional thermo-sensitive TRP channels: Implications for dentin sensitivity. Pain 152: 2211-2223, 2011.

32. Meng H, Li H, Ohe R, Naing YA, Yang S, Kabasawa T, Kato T, Osakabe M, Ohtake H, Ishida A, et al: Thymic stromal lymphopoietin in tonsillar follicular dendritic cells correlates with elevated serum immunoglobulin A titer by promoting tonsillar immunoglobulin A class switching in immunoglobulin A nephropathy. Transl Res 176: 1-17, 2016.

33. Masuda A, Nishikawa T, Yamamoto $\mathrm{T}$ and Kobayashi $\mathrm{M}$ : Simple method for photoshop-aided double immunohistochemistry-usage of 'image stack' function. Histopathology 53 : 609-610, 2008

34. Wada K, Maeda K, Tajima K, Kato T, Kobata T and Yamakawa M: Expression of BAFF-R and TACI in reactive lymphoid tissues and B-cell lymphomas. Histopathology 54: 221-232, 2009.

35. Yamamoto A, Takahashi K, Saito S, Tominaga M and Ohta T: Two different avian cold-sensitive sensory neurons: Transient receptor potential melastatin 8 (TRPM8)-dependent and -independent activation mechanisms. Neuropharmacology 111: 130-141, 2016.

36. Weyer AD and Lehto SG: Development of TRPM8 antagonists to treat chronic pain and migraine. Pharmaceuticals (Basel) 10 pii: E37, 2017.

37. Falini B, Fizzotti M, Pucciarini A, Bigerna B, Marafioti T, Gambacorta M, Pacini R, Alunni C, Natali-Tanci L, Ugolini B, et al: A monoclonal antibody (MUM-1p) detects expression of the MUM-1/IRF4 protein in a subset of germinal center B cells, plasma cells, and activated T cells. Blood 95 2084-2092, 2000

38. Zhang X, Park CS, Yoon SO, Li L, Hsu YM, Ambrose C and Choi YS: BAFF supports human B cell differentiation in the lymphoid follicles through distinct receptors. Int Immunol 17: 779-788, 2005

39. Simon S and Labarriere N: PD-1 expression on tumor-specific T cells: Friend or foe for immunotherapy? Oncoimmunology 14: e1364828, 2017.
40. Kang JE, Hwang SH, Lee JH, Park DY and Kim HH: Effects of RBC removal and TRIzol of peripheral blood samples on RNA stability. Clin Chim Acta 412: 1883-1885, 2011.

41. Almeida SM, Raboni SM, Nogueira MB and Vidal LR: Red blood cells in cerebrospinal fluid as possible inhibitory factor for enterovirus RT-PCR. Arq Neuropsiquiatr 74: 810-815, 2016.

42. Siebolts U, Varnholt H, Drebber U, Dienes HP, Wickenhauser C and Odenthal M: Tissues from routine pathology archives are suitable for microRNA analyses by quantitative PCR. J Clin Pathol 62: 84-88, 2009.

43. Zhang L and Barritt GJ: TRPM8 in prostate cancer cells: A potential diagnostic and prognostic marker with a secretory function? Endocr Relat Cancer 13: 27-38, 2006.

44. Chuang HH, Neuhausser WM and Julius D: The super-cooling agent icilin reveals a mechanism of coincidence detection by a temperature-sensitive TRP channel. Neuron 43: 859-869, 2004.

45. Tartakoff AM and Vassalli P: Plasma cell immunoglobulin secretion: Arrest is accompanied by alterations of the golgi complex. J Exp Med 146: 1332-1345, 1977.

46. Kiessling A, Stevanovic S, Füssel S, Weigle B, Rieger MA, Temme A, Rieber EP and Schmitz M: Identification of an HLA-A*0201-restricted T-cell epitope derived from the prostate cancer-associated protein prostein. Br J Cancer 90: 1034-1040, 2004. Attribution-NonCommercial-NoDerivatives 4.0 International (CC BY-NC-ND 4.0) License. 